Edited by Allan Beveridge, Femi Oyebode and Rosalind Ramsay

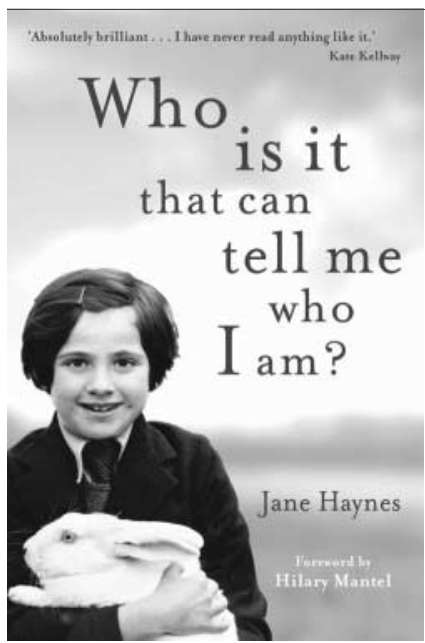

\section{Depression. Cognitive Behaviour Therapy with Children and Young People}

By C. Verduyn, J. Rogers \& A. Wood. Routledge. 2009. f19.99 (pb). 224pp. ISBN: 9780415399784

Bipolar Disorder in Young People. A Psychological Intervention Manual

By C.A. Macneil, M. K. Hasty, M. Berk \& J. Scott.

Cambridge University Press 2009. £29.99 (pb). 198pp. ISBN: 9780521719360

\section{Who Is It That Can Tell Me Who I Am?}

By Jane Haynes. Constable \& Robinson. 2009 f7.99 (pb). 352pp. ISBN: 9781845299729

The three books all in their own way attempt to answer the gnarly question of how best to do therapy. In light of the recent warnings about selective serotonin reuptake inhibitors and the best evidence that talking treatments should be first-line treatment for adolescent depression, this trio could not have come at a better time.

Depression. Cognitive Behaviour Therapy with Children and Young People is a welcome guide to treating depression in adolescents and young adults. One of the frustrations in clinical practice is seeing the success of cognitive-behavioural therapy in randomised controlled trials but not having access to manualised treatments that work in the real world where there are comorbidities and time constraints and few, if any, psychology assistants competing for cases. (For younger children, there is Think Good - Feel Good, by Paul Stallard (Wiley Blackwell, 2002). This compilation of worksheets, real-world case examples and practical information is a must-buy for any child and adolescent mental health clinician.)

Bipolar Disorder in Young People. A Psychological Intervention Manual was developed by clinicians working in the specialist bipolar team and the early psychosis prevention and intervention centre in Melbourne, Australia. This is not just a 'how to do therapy' book - it also deals with those difficult and specific developmental issues which child and adolescent psychiatrists are all too familiar with. For instance, there is a detailed case history with a verbatim transcript of how to apply motivational interviewing techniques to a teenager with bipolar disorder who sees his substance misuse as potentially helpful. I particularly enjoyed the sections on good-bye letters, working to reduce stigma and shame, and role play. The challenges of how to encourage adolescents to engage in social rhythm regulation are also explored. I have been trying it out in clinic. It works.

Both books contain a number of appendices and worksheets (including excellent resources to download) that allow clinicians to try out the techniques they have learnt straight away. My only gripe is that the section on assessment is rather long and wordy, and the sections on cognitive techniques rather shorter, but this is a trivial objection.

In Who Is It That Can Tell Me Who I Am?, psychotherapist Jane Haynes writes as the archetypal wounded healer. Although she says early on in the book that she dislikes the term, in the first half she focuses on her own psychotherapy and ends with a moving account of her murdered son-in-law, to whose children this book is dedicated. In the style but alas not the flair of Oliver Sacks, Haynes shares a number of case histories, including her own.

In contrast to the evidence-based manualised therapies presented in the other two books, Haynes's own analysis took place five times a week over 13 years. By her account, she was 'ensnared into interminable analysis'. She describes how, as a child, her mother left her in a pram in the department store before eventually leaving her for good to be cared for by her father who suffered from a frontal brain tumour and bizarre behaviour.

The first half of the book is presented as a letter to Haynes's analyst, who has now died. I was by turns voyeuristic, curious and then bored. It was rather like discovering a box of someone else's love letters. I was uncomfortable with the accounts, in the second half the book, of Haynes's own patients. There appeared to be a lot of unlimited disclosure of confidential information, with retrospective justification. Patients were asked for permission but it is hard to imagine feeling able to say no to a clinician with whom one has such a close analytic relationship. The stories were engaging but I was unsure for what purpose they were being shared.

Sabina Dosani Consultant Child and Adolescent Psychiatrist, Leapfrog Clinic, PO Box 137213 Parnell, Auckland, New Zealand.

Email: sabina.dosani@leapfrogclinic.co.nz

doi: 10.1192/bjp.bp.109.068460

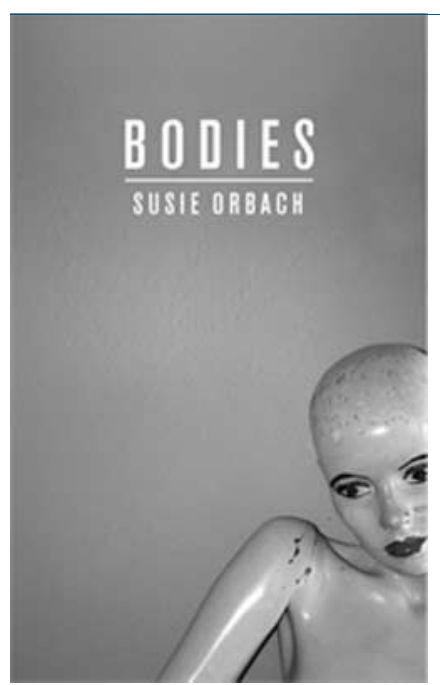

\section{Bodies}

By Susie Orbach

Profile Books. 2009.

f10.99 (pb). 160pp.

ISBN: 9781846680199

In Bodies Susie Orbach continues her crusade to show us the variety of ways in which bodies (mainly, but not only, female bodies) are acted upon by their 'owners' to create monuments to personal, perhaps parental/maternal neglect. We are obsessed, she observes, with our frail corporeality, something upon which we can exercise control, whereas the psyche seems so much less accessible.

As we have come to expect from Orbach, this is a fine exercise in both writing and expression, in a very particular genre: the 
psychoanalytic kind. And perhaps that is where most mortals, and I include most psychiatrists, will be left panting, trying to keep up with the less-than-straightforward perspective that an analysand and their analyst inhabit daily. To them, the notion of expressing oneself through creating physical and emotional feelings within an observer is commonplace. To us, hard to comprehend: the immaculate client creating a sense of bodily disgust in the (equally immaculate) Orbach; the analyst dressing for her patient, aware that she needs to compete for her own sense of beauty; expressing her client's needs within her own body. Yes, words do not do it, but physical discomfort does. One of the triumphs of this book is how simple, yet moving and beautiful an account Orbach provides of body dysmorphia and the illness it breeds in the sufferer.

Running through the landscape of Orbach's clinical analytic life is her long-term interest in neuroscience. She explores intelligent (if slimly tenable on current evidence) views about brain mechanisms involved in body dysmorphia and its manifestations. For most readers who will have no psychoanalytic experience, the language may put off. But I would encourage all clinicians working in psychiatric services (especially with women) to persist. At 160 pages, this is not a great burden on one's time. And the investment is likely to bear fruit in a better understanding of some of the more baffling symptoms and disorders we encounter in psychiatric practice.

Kathryn Abel University of Manchester, Centre for Women's Mental Health, Manchester, UK. Email: kathryn.abel@manchester.ac.uk

doi: 10.1192/bjp.bp.109.070995

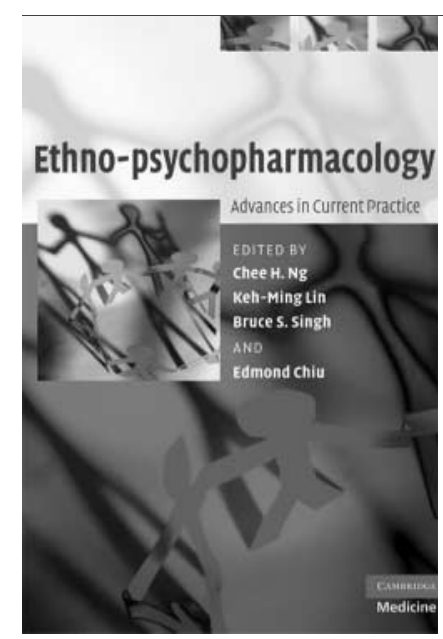

Ethno-

Psychopharmacology: Advances in Current Practice

Edited by Chee H. Ng, Keh-Ming Lin, Bruce S. Singh \& Edmond Chiu.

Cambridge University Press. 2008. £57.00 (hb). 200pp.

ISBN: 9780521873635

Clinicians have always been aware of individual differences in the clinical response to psychotropic drugs. Much of this is due to differences at the biological level, specifically to genetic polymorphisms. This variability is what pharmacogenetics, with its promise of individualised pharmacotherapy, seeks to help us understand and respond to. However, other factors such as what we eat, our habits and lifestyle, which may ultimately modify the expression of our genes, often have more immediate consequences for how our bodies react to the drugs we use. Indeed, whether we even accept to take the drugs in the first place may be determined not by our genes but by factors in our immediate cultural and ethnic environment.

A consideration of ethno-pharmacology is not simply a discussion of ethnic differences in the pharmacokinetics of drugs that may have genetic origin. This book has been compiled with an understanding of the broad issues involved in psychotropic drug use in the context of unique ethnic experiences. It is an informed attempt to sensitise clinicians to what is currently known about ethnic differences in response to psychotropic drugs, especially in so far as those differences manifest among populations in Asia. The issues addressed include cultural influence on psychopathology, pharmacogenetics, complementary medicines and pharmaco-economics.

Ethno-pharmacology has received more research attention among Asian populations than among any other group. That is probably a historical accident rather than a proof that ethnopharmacology is irrelevant to ethnic groups elsewhere. Indeed, this book attests to this by showing some of the evidence as it relates to Hispanic and African American populations. The chapter by William Lawson on inter-ethnic variations in psychotropic response in African Americans and that by Deborah Flores and Ricardo Mendoza on Hispanics are an eye opener, showing that the issues involved transcend one ethnic group.

The book is a good addition to the library of anyone interested in the broad topic of cultural psychiatry. It reminds us that the importance of culture and ethnicity is not only to be seen in the context of symptom expression, or even in that of prevalence of disorders, but in the equally important context of how and why we often respond or fail to respond to psychotropic drugs. We may be expectant about the tantalising prospect of individualised pharmacotherapy when pharmacogenetics delivers on its promise. However, as the chapter by Chee Ng shows, wise clinicians will always be conscious of the fact that issues other than genetics will remain important in any consideration of whether a drug intervention will do good or harm.

Oye Gureje Department of Psychiatry, University of Ibadan, University College Hospital, Ibadan, Nigeria. Email: ogureje@comui.edu.ng

doi: 10.1192/bjp.bp.100.077438

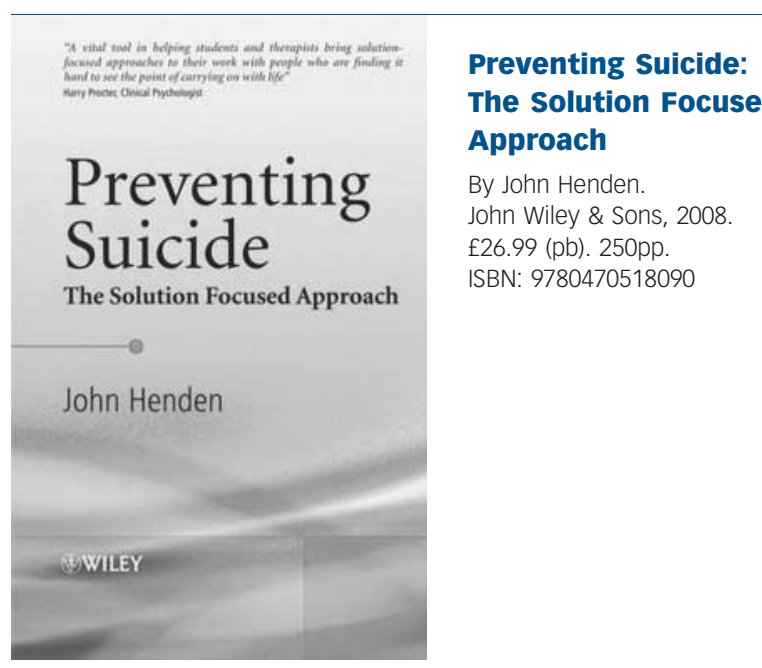

Solution-focused brief therapy (SFBT) is clearly modish. In addition to its apparent popularity, SFBT has a growing number of applications - everything from juvenile offending to orthopaedic rehabilitation and preventing suicide - a mega-trend according to the author of this book. The basic premise of SFBT is relatively straightforward - by focusing on hopes for the future, 'solution thoughts and behaviours' and strengths, positive change will be facilitated. Therapists in session work towards 'problem-free talk' 